\title{
Different Effect of Static Stretching and Neurodynamic Technique in Increasing Hamstring Flexibility on Hamstring Tightness
}

\author{
Dany Pramuno Putra ${ }^{\mathrm{a}}$, Gadis Meinar Sari ${ }^{\mathrm{a}}$, Dwikora Novembri Utomo ${ }^{\mathrm{a} *}$ \\ a danypramunoputra2@gmail.com \\ ${ }^{a}$ Master Program of Sport Health Science, Faculty of Medicine, Universitas Airlangga, Surabaya, Indonesia
}

\begin{abstract}
Background: Poor hamstring muscle flexibility is one of the most common risk factors for hamstring injuries. This poor flexibility condition often occurs in individuals who experience hamstring tightness. Static stretching and neurodynamic technique are exercises to increase the flexibility of the hamstring muscle. Purpose: This study aims to determine the difference in the effect of static stretching and neurodynamic technique exercises in increasing hamstring muscle flexibility on hamstring tightness. Material/Methods: Quasi-experimental pre and post-test two-group design. 16 male student-athletes were randomly divided into 2 groups, static stretching exercises group, and neurodynamic technique exercises group. Each group consists of 8 people. The hamstring flexibility measurement used in this study is the straight leg raise (SLR) examination and will be evaluated in four weeks. Result: The static stretching exercise intervention had a significant effect on the flexibility of the hamstring muscles $(p<0.05)$. Likewise, the neurodynamic technique exercise intervention also had a significant effect on hamstring muscle flexibility $(\mathrm{p}<0.05)$. However, there was no significant difference in the increase in hamstring muscle flexibility after being given both exercises $(p>0.05)$.
\end{abstract}

Keywords: hamstring tightness; neurodynamic technique; static stretching

\section{Introduction}

The hamstring muscle is one of the lower extremity muscles that tend to shorten and is often injured. Hamstring muscle injuries often occur in sports that involve shortening-lengthening cycles, such as soccer, basketball, and volleyball (Alzahrani et.al., 2015). Poor hamstring muscle flexibility is one of the most common risk factors for hamstring injuries. This is due to the occurrence of tension in the musculotendinous structure which reduces the ability of the muscle to lengthen rapidly without injury. This poor flexibility condition often occurs in individuals who experience hamstring tightness (Babu, et. al., 2015). The prevalence of hamstring tightness in students aged 18-25 years reached 96\%. In addition, Mahadik's research stated that the prevalence of hamstring tightness in students aged $18-25$ years was $82 \%$ when measured using active knee extension measurements (Koli, et.al., 2018).

Decreased flexibility of the hamstring muscles is characterized by a limited range of motion on straight leg raise (SLR) examination due to neurodynamic changes that affect peripheral nerves. Neurodynamic 
abnormalities in the posterior lower extremities can affect muscle length at rest and cause changes in the perception of stretch or pain (Areeudomwong et.al., 2016). There are various interventions used to increase muscle flexibility, including static stretching exercises and neurodynamic techniques exercise. Static stretching is an intervention that has been used for many years to help increase muscle length by stretching the muscle until it reaches the point of maximum tolerable tension (Heshmatipour, et. al., 2019). While the neurodynamic technique is believed to be able to change muscle neurodynamics and cause sensation modification, so it will increase muscle flexibility (Areeudomwong et. al., 2016). Therefore, this study aims to determine the difference in the effect of static stretching and neurodynamic technique exercises in increasing hamstring muscle flexibility on hamstring tightness.

\section{Materials and Methods}

\subsection{Study design}

Quasi-experimental pre and post-test two-group design. It consisted of two treatment groups where group 1 was given static stretching exercises and group 2 was given neurodynamic technique exercises.

\subsection{Subjects}

Subjects were 16 male student-athletes who were randomly divided into 2 groups. Each group consists of 8 people.

Inclusion criteria: male students, aged 19-22 years, have a normal body mass index (BMI), are active in a high-intensity sport of shortening-lengthening cycles, and have hamstring tightness, as indicated by the results of an SLR examination of less than 75 o.

Exclusion criteria: having plates (implants) in the lower limbs, a history of fractures in the lower limbs (with or without realignment process), a history of surgery to repair joint capsules, ligaments, muscles, and nerves, and a history of or experiencing Hernia Nucleus Pulposus (HNP).

\subsection{Measurement}

The hamstring flexibility measurement used in this study is the straight leg raise (SLR) examination and will be evaluated in four weeks.

\subsection{Intervention}

Group 1 will be given a static stretching exercise intervention, with the subject's hip being lifted passively to $90^{\circ}$ flexion, then the subject's knee is slowly extended until the subject feels a tolerable tension in the hamstring muscles. This position was maintained for 30 seconds and was repeated in 3 sets (Ayala et al., 2013). Meanwhile, group 2 will be given a neurodynamic technique intervention, which will be done by placing the patient in a chair, bending them back, placing both hands behind the lower back, hanging both legs, and followed by two movements. The first movement is neck flexion, knee flexion, ankle plantar flexion, and the second movement is neck extension, knee extension, ankle dorsiflexion. The two movements are actively performed alternately, held for 60 seconds, and repeated 5 times. Both static stretching and neurodynamic technique exercises were performed 3 times/week for 4 weeks (Areeudomwong et.al., 2016). 


\subsection{Statistical analysis}

The data obtained from this study will then be analyzed using the SPSS V.22 application with a significance level of $\mathrm{p}<0.05$. The data analysis process started from descriptive analysis, normality test, effect test (paired t-test), homogeneity test (Lavene's test), and independent t-test.

\section{Results}

Characteristics of the subjects in this study were obtained by descriptive statistical analysis which included age, body mass index, and angle of straight leg raises (SLR). Based on the descriptive analysis showed that the research subjects were according to the controlled criteria (Table 1).

Table1. Descriptive test of sample characteristics

\begin{tabular}{lcc}
\hline & Table1. Descriptive test of sample characteristics \\
Characteristic & $\begin{array}{c}\text { Static stretching group } \\
(\mathbf{n}=\mathbf{8})\end{array}$ & $\begin{array}{c}\text { Neurodynamic technique group } \\
(\mathbf{n}=\mathbf{8})\end{array}$ \\
\cline { 2 - 3 } & Mean \pm SD & Mean \pm SD \\
\hline Age (year) & $20,50 \pm 0,535$ & $20,38 \pm 0,518$ \\
Body mass index $\left(\mathbf{k g} / \mathbf{m}^{\mathbf{2}}\right)$ & $23,33 \pm 0,538$ & $23,69 \pm 0,358$ \\
SLR test $\left(^{(}\right)$ & $70,50 \pm 3,464$ & $71,13 \pm 2,357$ \\
\hline
\end{tabular}

SLR measurement data before and after treatment in the static stretching group and the neurodynamic technique group showed an increase in the SLR value based on the average value of the pre-test and post-test. The data from the SLR measurements in the two groups were also normally distributed ( $\mathrm{p}>0.05$ ), so the statistical test used parametric tests to test the hypothesis (Table 2).

Table 2. Mean, standard deviation, and normality test in static stretching group and neurodynamic technique group

\begin{tabular}{lllll}
\hline \multicolumn{1}{c}{ Group } & n & Mean \pm SD $\left(^{(}\right)$ & \multicolumn{1}{c}{ p-value } & Normality \\
\cline { 2 - 5 } Static stretching group & Pre test & 8 & $70,50 \pm 3,464$ & 0,125 \\
\cline { 2 - 5 } & Post test & 8 & $80,88 \pm 2,532$ & 0,662 \\
\hline Neurodynamic technique & Pre test & 8 & $71,13 \pm 2,357$ & 0,284 \\
\cline { 2 - 5 } & Proup & 8 & $81,63 \pm 2,134$ & 0,105 \\
\hline
\end{tabular}


Table 3. Paired t-test in static stretching group and neurodynamic technique group

\begin{tabular}{|c|c|c|c|c|}
\hline \multirow{2}{*}{\multicolumn{2}{|c|}{ Group }} & \multirow{2}{*}{$\mathbf{n}$} & \multirow{2}{*}{ Mean \pm SD $\left({ }^{\circ}\right)$} & \multirow{2}{*}{$\begin{array}{c}\text { p-value } \\
\text { Paired t-test }\end{array}$} \\
\hline & & & & \\
\hline \multirow{2}{*}{ Static stretching group } & Pre test & 8 & $70,50 \pm 3,464$ & \multirow{2}{*}{0,000} \\
\hline & Post test & 8 & $80,88 \pm 2,532$ & \\
\hline \multirow{2}{*}{$\begin{array}{l}\text { Neurodynamic technique } \\
\text { group }\end{array}$} & Pre test & 8 & $71,13 \pm 2,357$ & \multirow{2}{*}{0,000} \\
\hline & Post test & 8 & $81,63 \pm 2,134$ & \\
\hline
\end{tabular}

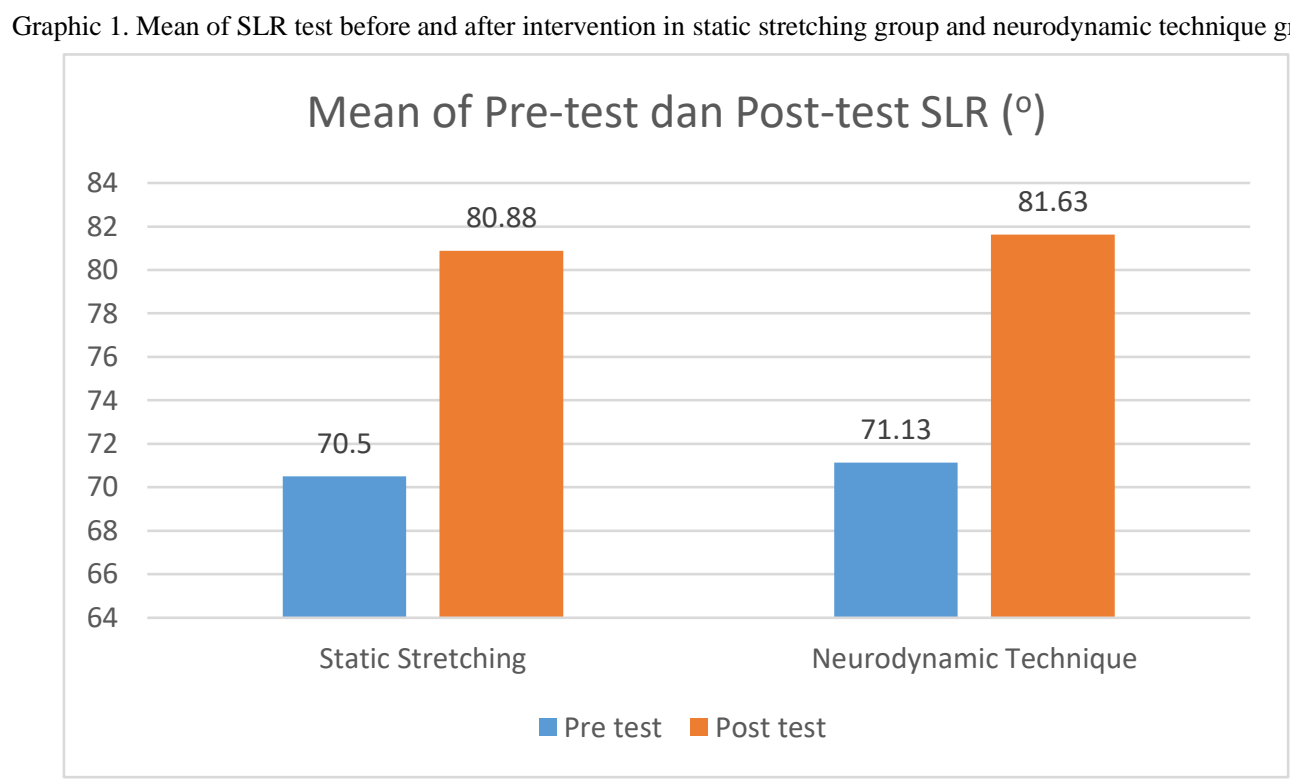

Based on table 3, the effect test using the paired t-test showed that the static stretching exercise intervention had a significant effect on the flexibility of the hamstring muscles $(p<0.05)$. Likewise, the neurodynamic technique exercise intervention had a significant effect on hamstring muscle flexibility $(\mathrm{p}<0.05)$. The static stretching group experienced an increase in the average SLR value in the post-test with a difference of $10.38^{\circ}$, while in the neurodynamic technique group there was also an increase in the average SLR value in the posttest with a difference of $10.5^{\circ}$ (Graphic 1 ). 
Table 4. Homogeneity test with Lavene's test

\begin{tabular}{|c|c|c|c|}
\hline \multirow[b]{2}{*}{ Group } & & \multirow[b]{2}{*}{$\operatorname{Mean} \pm \operatorname{SD}\left({ }^{\circ}\right)$} & \multirow[t]{2}{*}{ p-value } \\
\hline & & & \\
\hline \multirow[t]{2}{*}{ Static Stretching } & Pre test & $70,50 \pm 3,464$ & \\
\hline & & & 0,190 \\
\hline \multirow[t]{3}{*}{ Neurodynamic Technique } & Pre test & $71,13 \pm 2,357$ & \\
\hline & \multicolumn{2}{|c|}{ Table 5. Independent t-test } & \\
\hline & & & p-value \\
\hline \multirow[t]{2}{*}{ Group } & & Mean \pm SD $\left(^{\circ}\right)$ & \\
\hline & & & Independent t-test \\
\hline \multirow[t]{2}{*}{ Static Stretching } & Post test & $80,88 \pm 2,532$ & \\
\hline & & & 0,532 \\
\hline Neurodynamic Technique & Post test & $81,63 \pm 2,134$ & \\
\hline
\end{tabular}

The results of the homogeneity test calculation using Lavene's test obtained a p-value of $0.190(p>0.05)$, it can be concluded that the variance in both groups is the same or homogeneous (Table 4). Therefore, the calculation of the difference test was then carried out using an independent t-test, from the SLR value after the intervention in both groups, and the p-value was 0.532 ( $p>0.05$ ). It can be concluded that there is no difference in the increase in hamstring muscle flexibility after the intervention in the static stretching treatment group and the neurodynamic technique treatment group (Table 5).

\section{Discussion}

The results obtained from this study prove that static stretching exercises have a significant effect on increasing the flexibility of the hamstring muscles. The results obtained are following previous research by Pagare, et. al. (2014) who proved that static stretching exercises can increase the flexibility of the hamstring muscles. Various theories explained the mechanism of increasing muscle flexibility due to the static stretching exercise, including the theory of viscoelastic deformation. Concerning the theory of viscoelastic deformation, static stretching causes an increase in muscle length due to the supple character of the muscles and muscle elasticity. The systematic review research conducted by Medeiros, et. al. (2016) also mentioned that static stretching exercises are effective in increasing the flexibility of the hamstring muscles, based on the mechanism of increasing the number of sarcomeres and muscle viscoelasticity which can increase muscle length and reduce muscle tension. A study conducted by Sato, et. al. (2020) also mentions that static stretching exercises can cause an increase in joint range of motion, a decrease in passive stiffness, and a decrease in the modulus of muscle elasticity. When there is a decrease in the modulus of muscle elasticity, muscle tension will decrease (Nakao, et. al., 2018).

This study also proves that neurodynamic technique exercise has a significant effect on increasing hamstring muscle flexibility under hamstring tightness conditions. The results obtained are following previous research by Areeumdomwong, et. al. (2016), who proved that neurodynamic technique exercises can increase the flexibility of the hamstring muscles, which is related to the mechanism of decreasing mechanoreceptors 
and proprioceptors in the muscles, decreasing mechanosensitivity in the nerves, as well as lengthening the structure of the nerves and fascia which causes an increase in joint range of motion and flexibility of the hamstring muscles. In his research, Babu, et. al. (2015) stated that neurodynamic technique exercises are useful for changing the neurodynamic sensation of muscles and ultimately increasing the flexibility of the hamstring muscles. Neurodynamic technique exercise also causes an increase in nerve tension which causes the lengthening of the sciatic nerve and an increase in the flexibility of the hamstring muscles.

In addition, this study proves that both static stretching exercises and neurodynamic technique exercises are equally effective as interventions in hamstring tightness conditions that aim to increase the flexibility of the hamstring muscles. There was no significant difference in the increase in hamstring muscle flexibility after being given static stretching exercises and neurodynamic techniques, probably due to various mechanisms that have not been fully determined.

\section{Conclusion}

Static stretching and neurodynamic technique exercises have been shown to increase the flexibility of the hamstring muscles in conditions of hamstring tightness. Both exercises are equally effective in increasing the flexibility of the hamstring muscles so that there is no significant difference in the effect between the two.

\section{Acknowledgments}

The author is deeply indebted to the Faculty of Medicine, Universitas Airlangga.

\section{References}

Alzahrani, M. M., Aldebeyan, S., Abduljabbar, F., \& Martineau, P. A. (2015). Hamstring injuries in athletes: Diagnosis and treatment. JBJS Reviews, 3(6), 1-11.

Areeudomwong, P., Oatyimprai, K., \& Pathumb, S. (2016). A randomized, placebo-controlled trial of neurodynamic sliders on hamstring responses in footballers with hamstring tightness. Malaysian Journal of Medical Sciences, 23(6), 60-69.

Koli, B. K., \& Anap, D. B. (2018). Prevalence And Severity Of Hamstring Tightness Among College Student : A Cross-Sectional Study. 65-68.

Ayala, F., De Ste Croix, M., Sainz De Baranda, P., \& Santonja, F. (2013). Acute effects of static and dynamic stretching on hamstring eccentric isokinetic strength and unilateral hamstring to quadriceps strength ratios. Journal of Sports Sciences, 31(8), 831-839.

Heshmatipour, M., Esfandiari, A., Kazemi Naeini, M., Raei, M., Firoozpur, O., Shariatinia, N., \& Hushmandi, K. (2019). Effect of Active Dynamic Versus Passive Static Stretching on Hamstring Muscle Tightness in Healthy Female Students: A Randomized Trial Study. Hospital Practices and Research, 4(4), 134-138.

Medeiros, D. M., Cini, A., Sbruzzi, G., \& Lima, C. S. (2016). Influence of static stretching on hamstring flexibility in healthy young adults: Systematic review and meta-analysis. Physiotherapy Theory and Practice, 32(6), 438-445.

Nakao, G., Taniguchi, K., \& Katayose, M. (2018). Correction: Acute Effect of Active and Passive Static Stretching on Elastic Modulus of the Hamstrings. Sports Medicine International Open, 02(06), E200-E200.

Pagare, V. K., Ganacharya, P. M., Sareen, A., \& Palekar, T. J. (2014). Effect of neurodynamic sliding technique versus static stretching on hamstring flexibility in football players with short hamstring syndrome. Journal of Musculoskeletal Research, 17(2), 1-8.

Sato, S., Kiyono, R., Takahashi, N., Yoshida, T., Takeuchi, K., \& Nakamura, M. (2020). The acute and prolonged effects of 20-s static stretching on muscle strength and shear elastic modulus. PLoS ONE, 15(2), 1-10.

Vinod Babu, K. (2015). Immediate Effect of Neurodynamic Sliding Technique Versus Mulligan Bent Leg Raise Technique on Hamstring Flexibility in Asymptomatic Individuals. International Journal of Physiotherapy, 2(4), 658-666. 